\title{
MEF2 and the Right Ventricle: From Development to Disease
}

\author{
Katharine R. Clapham ${ }^{1 \dagger}$, Inderjit Singh ${ }^{2 \dagger}$, Isabella S. Capuano ${ }^{1,3}$, Sudarshan Rajagopal ${ }^{4}$ \\ and Hyung J. Chun ${ }^{1 *}$
}

${ }^{1}$ Section of Cardiovascular Medicine, Department of Internal Medicine, Yale Cardiovascular Research Center, Yale School of Medicine, New Haven, CT, United States, ${ }^{2}$ Section of Pulmonary, Critical Care and Sleep Medicine, Department of Internal Medicine, Yale University School of Medicine, New Haven, CT, United States, ${ }^{3}$ Choate Rosemary Hall, Wallingford, CT, United States, ${ }^{4}$ Division of Cardiology, Department of Medicine, Duke University Medical Center, Durham, NC, United States

\section{OPEN ACCESS}

Edited by:

Susumu Minamisawa,

Jikei University School of Medicine, Japan

Reviewed by: Yibin Wang

University of California, Los Angeles, United States

Isao Shiraishi,

National Cerebral and Cardiovascular Center, Japan

*Correspondence:

Hyung J. Chun

hyung.chun@yale.edu

tThese authors have contributed equally to this work

Specialty section:

This article was submitted to Heart Failure and Transplantation,

a section of the journal

Frontiers in Cardiovascular Medicine

Received: 08 January 2019 Accepted: 06 March 2019 Published: 28 March 2019

Citation: Clapham KR, Singh I, Capuano IS, Rajagopal S and Chun HJ (2019) MEF2 and the Right Ventricle: From

Development to Disease.

Front. Cardiovasc. Med. 6:29. doi: 10.3389/fcvm.2019.00029
Pulmonary arterial hypertension is a progressive and ultimately life-limiting disease in which survival is closely linked to right ventricular function. The right ventricle remains relatively understudied, as it is known to have key developmental and structural differences from the left ventricle. Here, we will highlight what is known about the right ventricle in normal physiology and in the disease state of pulmonary arterial hypertension. Specifically, we will explore the role of the family of MEF2 (myocyte enhancer factor 2) transcription factors in right ventricular development, its response to increased afterload, and in the endothelial dysfunction that characterizes pulmonary arterial hypertension. Finally, we will turn to review potentially novel therapeutic strategies targeting these pathways.

Keywords: right ventricle, MEF2, pulmonary hypertension, HDAC, hypertrophy

\section{INTRODUCTION}

Pulmonary arterial hypertension (PAH) remains a significant therapeutic challenge, despite ongoing advances in our body of knowledge of this devastating disease. In particular, no approved therapies to date seek to directly achieve improvement or preservation of the right ventricular (RV) function, despite compelling evidence that RV function is a critical determinant of clinical outcomes in PAH. Recent studies have begun to investigate strategies to preserve or improve RV function in the context of increased pulmonary vascular resistance (PVR), including application of left-sided heart failure treatments to RV failure. However, the two ventricles are uniquely distinct in their embryonic origins, and multiple studies have demonstrated that even in adult stages their gene expression profile is remarkably different, suggesting that "one size fits both" approach to left ventricular (LV) and RV failure may face challenges in demonstrating tangible clinical efficacy. In this review we discuss what is known about mechanisms of RV development and disease, and highlight recent advances that may lead to novel RV-based therapeutic strategies.

\section{THE NORMAL RV}

In the fetal circulation, because of its extensive network of capillaries, the placenta has the lowest vascular resistance. In contrast, the PVR is high because of the fluid filled lungs. Consequently, two right to left shunts connecting the pulmonary and systemic circulations are encountered in the fetal circulation, namely the foramen ovale and the ductus arteriosus. The fetal RV is a thick-walled chamber that ejects blood into the high resistance pulmonary vascular system. Starting week 12 of gestation to term, the RV wall thickness is comparable to that of the LV. At birth, the pulmonary circulation regresses into a low resistance, high capacitance system, and the RV is able to eject directly into the pulmonary circulation without having to bypass the lung via foramen ovale or ductus arteriosus. The RV thickness subsequently 
regresses, leading to the thin-walled RV as seen in normal adults (1). Although the molecular mechanism that initiates this process is uncertain, an intriguing hypothesis involves the loss of fetal cardiomyocyte hypertrophic and proliferative genes allowing for normal RV morphologic adaptation to its pulmonary circulation.

The RV chamber is smaller and produces less contractile force than its counterpart. However, the RV is able to achieve a similar cardiac output with lower energy expenditure. How is this possible? One of the reasons lies in the orientation of the RV fibers, which is distinct from that of the LV. The RV free wall is made of superficial, circumferentially oriented fibers and deeper longitudinally oriented myocardial fibers, while the LV is made up primarily of circumferentially oriented fibers (1). At the end of diastole, the RV free wall is $2-3 \mathrm{~mm}$ in thickness while the LV free wall is 8 to $11 \mathrm{~mm}^{2}$. This thin longitudinal fiber orientation allows for a greater RV end-diastolic volume and surface area per volume of blood ensuring an identical stroke volume as the LV with lower energy expenditure (2). The longitudinal fiber orientation is also responsible for the peristaltic like RV contraction that begins at the inflow region before proceeding to the mid-wall and finally the RV outflow tract. The inflow region of the RV contracts $\sim 25-50$ milliseconds before the outflow region (3). This peristaltic wave of contraction dilates the proximal pulmonary artery, priming it to receive the ejected stroke volume thereby facilitating RV stroke volume. Continued ejection of RV stroke volume is further enhanced by the low resistance and high capacitance nature of the normal pulmonary circulation. The RV is able to eject before and wellbeyond attainment of peak RV systolic pressure. In fact, $\sim 60 \%$ of the RV stroke volume can be ejected after peak RV systolic pressure (4).

The fiber orientation of the RV also explains its contractile nature, which is characterized by longitudinal shortening of the septum and transverse motion of the free wall towards the interventricular septum during systole (1). The oblique contraction of the septal fibers generates an ejection fraction of $\sim 60 \%(5,6)$ and plays an important role in normal RV systolic function. However, contraction of the RV free wall, which generates an ejection fraction of $\sim 30 \%$, plays an integral part in preserving RV function when septal akinesia or hypokinesia is commonly encountered following cardiac surgery. Incidentally, the oblique myocardial fibers of the LV free wall are in continuum with the superficial circumferential fibers of the RV free wall and also contribute significantly to RV contraction and pulmonary blood flow $(7,8)$. This systolic ventricular dependence may explain in part why the placement of an LV assist device in patients with LV systolic dysfunction with associated mild pulmonary hypertension $(\mathrm{PH})$ can often precipitate acute RV failure (9).

The structural differences between the ventricular chambers account for their differing adaptive response to increasing preload and afterload. The more muscular LV, with its circumferentially arrayed fibers, is able to withstand sudden increases in afterload, but is less adaptive to increases in preload. On the other hand, the RV is able to accommodate large increases in venous return that is typical of the physiological response to exercise. This is likely because the normal RV is able to retain its shape rather than stretch, allowing it to adapt to increasing preload. The highly compliant $\mathrm{RV}$ is also able to function normally for decades in pathogenic states of increased preload, such as that seen in left to right intracardiac shunt defects (1). However, in scenarios of increasing RV afterload encountered in $\mathrm{PH}$, the RV falters.

\section{RV ADAPTATION TO PAH}

Although the initial insult in PAH implicates the pulmonary vasculature, the functional state, exercise capacity, and survival of patients with PAH is closely linked to RV function (10). $\mathrm{RV}$ ejection fraction and end diastolic volume measured by cardiac magnetic resonance imaging (cMRI) have been shown to be independent predictors of mortality in PAH irrespective of afterload, further emphasizing the significance of RV function as a prognostic factor in PAH (11).

RV adaptation to PAH is a complex process that not only relies on the severity of pulmonary vascular disease, but also on the interaction between neuro-hormonal activation, coronary perfusion, and myocardial metabolism $(12,13)$ (Table 1). Other factors that may influence RV adaptation include the underlying etiology of PAH, the age of onset, gender, ethnicity, as well as genetic and epigenetic factors (13). For example, males with $\mathrm{PAH}$ have worse RV function at initial presentation compared to their female counterparts (14), while the poorer outcomes observed in patients with scleroderma-associated PAH compared to idiopathic PAH may in part be related to the lower intrinsic RV contractility observed despite encountering similar RV afterload (15).

\section{ALTERATIONS IN RV GEOMETRY AND VENTRICULO-ARTERIAL COUPLING}

The initial response of the RV to a chronic increase in afterload is to increase its contractile reserve to match the increasing afterload. This homeometric adaptation is achieved through RV myocyte hypertrophy leading to a concentric remodeling pattern, which is characterized by a higher mass-to-volume ratio that allows for preservation of RV contractile function (13). The matching of RV contractility (termed end-systolic elastance, Ees) and its afterload (termed arterial elastance, Ea) describes RV-PA coupling and its preservation allows for optimal RV functioning at minimal energy cost (16).

When the RV is no longer able to augment its contractile force in the face of increasing afterload, it shifts to rely on hetereometric or volumetric adaptation (i.e., the FrankStarling mechanism) to sustain its flow output in response to increasing metabolic demand (17). The decreasing RV stroke volume leads to a compensatory increase in the heart rate, which in turn further increases the Ea (18). The resulting increase in Ea with failure to mount a corresponding increase in Ees leads to RV-PA uncoupling seen in advanced stages of the disease and dynamically during exercise $(17,19)$. This maladaptive remodeling pattern is characterized by more eccentric hypertrophy and worsening RV systolic and diastolic 
TABLE 1 | Characteristics of an adaptive and maladaptive remodeling pattern of the right ventricle in pulmonary hypertension.

\begin{tabular}{|c|c|c|}
\hline Characteristic & Adaptive remodeling & $\begin{array}{l}\text { Maladaptive } \\
\text { remodeling }\end{array}$ \\
\hline \multicolumn{3}{|l|}{ RV MORPHOLOGY } \\
\hline RV size & $\begin{array}{l}\text { Normal size to mild } \\
\text { dilatation }\end{array}$ & Enlarged RV \\
\hline RV hypertrophy & Eccentric & Concentric \\
\hline Mass-to-volume ratio & Higher & Lower \\
\hline RV fibrosis & Absent & Present \\
\hline \multicolumn{3}{|c|}{ INTRINSIC RV FUNCTION } \\
\hline RV-PA coupling & $\begin{array}{l}\text { Preserved or mild } \\
\text { reduction }\end{array}$ & Reduced \\
\hline RV contractile reserve & Preserved & Reduced \\
\hline $\begin{array}{l}\text { Resting RV ejection } \\
\text { fraction }\end{array}$ & $\begin{array}{l}\text { Normal to mild } \\
\text { reduction }\end{array}$ & Reduced \\
\hline RV-LV dyssynchrony & Present & Absent \\
\hline $\begin{array}{l}\text { RV perfusion with } \\
\text { macro and } \\
\text { microvascular ischemia }\end{array}$ & $\begin{array}{l}\text { Normal or mild } \\
\text { reduction perfusion } \\
\text { Normal serum troponin }\end{array}$ & $\begin{array}{l}\text { Reduced perfusion } \\
\text { Elevated } \\
\text { serum troponin }\end{array}$ \\
\hline RV metabolism & $\begin{array}{l}\text { Normal glucose uptake } \\
\text { with normal } \\
\text { mitochondrial oxidative } \\
\text { phosphorylation }\end{array}$ & $\begin{array}{l}\text { Increased glucose } \\
\text { uptake with increase } \\
\text { lactogenic glycolysis } \\
\text { and dysregulated fatty } \\
\text { acid oxidation }\end{array}$ \\
\hline $\begin{array}{l}\text { RV neuro-hormonal } \\
\text { signaling }\end{array}$ & $\begin{array}{l}\text { Preserved B1 and DA } \\
\text { receptor signaling } \\
\text { Normal BNP }\end{array}$ & $\begin{array}{l}\text { Desensitization/down } \\
\text { regulation of B1and DA } \\
\text { receptor signaling } \\
\text { Elevated BNP }\end{array}$ \\
\hline
\end{tabular}

$R V$, right ventricle; $P A$, pulmonary artery; contractile reserve refers to ability of the $R V$ to increase its contractility in the face of increasing afterload; LV, left ventricle; $D A$, dopaminergic.

function (10). RV volumetric adaptation stretches the tricuspid valve annulus, further decreasing forward flow, hampering LV filling, and further increasing the RV end-diastolic volume of an already pressure-loaded RV.

Despite the augmented susceptibility of the RV to increasing afterload, fibrosis of a chronically pressure overload RV occurs less extensively compared with a pressure-overloaded LV (e.g., systemic hypertension or severe aortic stenosis) (10). The fibrosis is limited to the RV-septal insertion points and this may explain why patients with severe pulmonary hypertension (PH) are able to attain normal RV function following lung transplantation, despite having reduced RV function at the time of transplantation.

\section{ALTERATIONS IN RV METABOLISM}

The normal fetal RV is reliant on glycolysis and subsequent oxidative phosphorylation for ATP generation. However, in the normal adult RV, fatty acid oxidation becomes the primary mechanism for ATP generation for the RV and is responsible for $\sim 60-90 \%$ of energy production in cardiomyocytes (1). In contrast to the normal RV, which is able to alternate its substrate use from fatty acids to glucose as needed, the myocytes of a hypertrophied RV exhibit suppression of mitochondrial oxidative phosphorylation, dysregulated fatty acid oxidation, and glutaminolysis $(1,13)$. Thus, the primary source of fuel is dependent on lactogenic glycolysis as opposed to fatty acid or glucose oxidation. This shift from oxidative phosphorylation to lactogenic glycolysis, known as the Warburg effect, is frequently observed in oncogenesis. This phenomenon is also seen in pulmonary vascular cells and in the failing RV in $\mathrm{PAH}$ patients. Hypoxia inducible factor (HIF) $1 \alpha$ has been identified as a main regulator of the Warburg effect. It is possible that in the presence of increasing RV afterload and therefore compromised coronary perfusion, the cellular oxygen tension is reduced. Consequently, HIF- $1 \alpha$ is activated, leading to increased glucose uptake, increased expression glycolytic enzymes, decreased oxidative phosphorylation, increased lactate fermentation, and increased mitochondrial autophagy. Such reprogramming also leads to reduction in fatty acid oxidation (20).

Investigative studies have clearly demonstrated the importance of RV function as a major determinant of survival in patients with $\mathrm{PAH}$. Future studies need to incorporate hemodynamic, metabolomic, and imaging phenotyping to improve our diagnostic approach allowing for a precision medicine strategy with RV targeted therapies tailored to individual patients.

\section{RV DEVELOPMENT}

As delineated above, the RV is unique in its structure and adaptive response to changes in physiology. In understanding the singular properties of the RV, it is illuminating to return to cardiac development. Initial descriptions of cardiac development were drawn from observations made of avian embryos, but subsequent study has demonstrated a broad applicability of these findings across species (21). Cardiac precursor cells from the mesoderm migrate to form the bilateral heart fields in chicks or cardiac crescent in mice, and the coalescence of these cells leads to the formation of a linear heart tube $(22,23)$. The heart field has been historically divided into the primary and anterior heart fields, with the primary heart field differentiating earlier and giving rise to the inflow limb, and the anterior heart field forming the outflow limb (22). However, subsequent clonal analysis has given rise to a new classification system in which the cells of the first heart field (FHF) are recognized to be the origin of the LV, part of the RV, and atria, and the second heart field (SHF) forms the majority of the RV, atria, and outflow tract (22). This classification system follows Isl 1 expression to some degree, although more recent studies have indicated that $I s l 1$ is expressed in both heart fields (24-28). The heart tube subsequently undergoes rightward looping, forming and orienting the outflow tract relative to the future chambers of the heart, before the formation of the atrioventricular valves and cardiac chambers (23).

This complex series of events is orchestrated by a genetic program controlling cell fate. The earliest recognized marker of cardiac cells arising from the mesoderm is the transcription factor Mesp1, though Mesp1 labeled cells give rise to other 
mesoderm derived cell populations as well (29). Myocardial cell differentiation begins to occur in the cardiac crescent, and the SHF phenotype is driven by a regulatory network which includes ISLET1 and NKX2-5 (30). The anterior part of the SHF is characterized by expression of TBX1, FGF8, or FGF10 and activation of the $M e f 2 c$ enhancer, and gives rise to the RV and the outflow tract (30).

\section{MEF2 IN CARDIAC DEVELOPMENT}

Mef2c (Myocyte enhancer factor 2C), one of four members of the MEF2 family of transcription factors in vertebrates, is thus critical to the development of the RV and outflow tract. The members of the MEF2 family of MADS (MCM1, agamous, deficiens, SRF)-box transcription factors have a broad range of functions as transcriptional activators to govern pathways leading to cell differentiation, proliferation, and survival in a variety of cell types (31). The highest expression of Mef2 genes is in the striated muscles and brain, although MEF2 is expressed in most tissues, including in smooth muscle and endothelium $(32,33)$. MEF2 serves a key role in vertebrate skeletal muscle differentiation, heart, neural crest, bone, vascular, and $\mathrm{T}$ cell development, and acts in adult tissues as a mediator of stressinduced remodeling (31).

The function of MEF2 in vertebrate cardiac development has been explored through the deletion and overexpression of Mef2 family members, demonstrating that MEF2 is required for cardiomyocyte differentiation and cardiac organogenesis. Mef $2 c$ is the first of the Mef2 genes to be expressed in mouse and chick embryos, initially in the mesoderm giving rise to the heart (32). The hearts of mice homozygous for a null mutation of Mef $2 c$ failed to undergo looping morphogenesis and develop a right ventricle (34). Cardiac overexpression of a dominant negative MEF2C protein inhibits cardiomyocyte differentiation, mediated in part by decreased GATA4 and NKX2-5 expression (35). Mef2a null mice are prone to sudden death in the perinatal period, and demonstrate cardiomyocyte myofibrillar disorganization followed by pronounced RV dilation (36). Mef $2 b$ and $M e f 2 d$ null mice demonstrate no developmental cardiac defects $(37,38)$.

The identification of abnormal MEF2 activity in individuals with congenital heart disease reinforces the relevance of the animal findings to human cardiac development. Screening of a patient population with congenital heart disease for mutations in candidate genes demonstrated a heterozygous missense $M E F 2 C$ mutation leading to decreased transcriptional activity in a family with double outlet RV and ventricular septal defect (39). Another study of 256 patients with cardiac outflow tract defects led to the identification of a sequence variant in $M E F 2 C$, which perturbed cardiac development in zebrafish when overexpressed (40).

\section{MEF2 IN CARDIAC HYPERTROPHY}

While it is clear that MEF2 has a critical role in cardiac development, there is a body of literature to suggest its role in cardiac hypertrophy. In animal models, MEF2 DNA binding activity is at its peak in the late fetal and neonatal heart, declines to low levels in adulthood, but is increased in the setting of volume or pressure overload (41). Mef2c expression and $\mathrm{MEF} 2 \mathrm{C}$ protein levels are increased in the myocardium of mice with angiotensin II induced cardiac hypertrophy, and MEF2C silencing by siRNA attenuates ventricular hypertrophy in an angiotensin II and aortic banding model of cardiac hypertrophy $(42,43)$. Transgenic mice with overexpression of MEF2A and MEF2C demonstrate increased ventricular weight, but decreased ventricular contractility; overexpression of MEF2D also causes pathologic cardiac remodeling $(37,44)$. Hypertrophic stimuli are thought to increase MEF2 activity through multiple mechanisms, including CaMK $\left(\mathrm{Ca}^{2+} /\right.$ calmodulin-dependent protein kinase) mediated nuclear export of inhibitory class IIa HDACS (HDAC4 and 5), MAPK induced phosphorylation of MEF2, and calcineurin signaling (45-50). Expression of a dominant negative form of MEF2 is also able to normalize the cardiac hypertrophy seen in calcineurin transgenic mice (51). Class IIa HDACs therefore act a "calcium sensitive" switch for cardiac hypertrophy through regulation of MEF2 (52).

While available evidence links MEF2 activity to LV hypertrophy, important questions remain in the context of RV function and adaptation to PH. First, the role of MEF2 in the transition between compensatory LV hypertrophy and subsequent dilation and decompensation remains inadequately defined-it is possible that MEF2 may be required to drive the initial hypertrophic response, but subsequent decompensation and worsening of ventricular function may involve other signals. Second, the studies of MEF2 in cardiac hypertrophy have focused predominantly on the $\mathrm{LV}$, with a relative dearth of information about the function of MEF2 in the RV response to increased afterload in PAH. This deficiency of evidence stems in part from the use of genetic tools that lack ventricular specificity. While Mef $2 c$-AHF-Cre transgenic mice have been utilized to label cells that derive from the second heart field to provide insight into cardiac development (53), similar approaches have not yet been undertaken in the investigation of the RV specific molecular mechanisms of disease.

A recent study has provided some insight into how MEF2 guides the RV response to increased afterload. As reviewed above, initially in PAH, the RV hypertrophies in a compensatory fashion, but ultimately decompensation and decline of RV function can follow. In a monocrotaline rat model of $\mathrm{PH}, \mathrm{MEF} 2 \mathrm{C}$ levels and nuclear localization increase in the RV in the first several weeks of compensatory RV hypertrophy, then decrease with RV decompensation (54). Downregulation of MEF2C in decompensated RV hypertrophy occurs through suppression of microRNA 208 (miR-208) and increased MED13/NCoR1 activity, a pathway also upregulated in the RV in response to the proinflammatory stimulus of TNF- $\alpha$ (54). MEF2 activity is known in other contexts to be regulated at transcriptional, post-transcriptional and post-translational levels, and while comparatively little is understood of MEF2 regulation in the setting of RV hypertrophy and decompensation, transcriptional levels of $M e f 2 c$ and $M e f 2 d$ are known to be increased in the absence of NCoR1, and NCoR1 in conjunction with HDAC3 and HDAC4 has been demonstrated to lead to posttranslational regulation of $\mathrm{MEF} 2 \mathrm{D}$ by altering its acetylation 
state (55). MicroRNA profiling of the RV in mice subjected to pulmonary artery constriction demonstrates initial upregulation of microRNAs, such as miR-208, promoting cardiac hypertrophy and cardiomyocyte survival, and an increase in proapoptotic and fibrotic microRNAs in the decompensated stage (56). Taken together, the available evidence suggests that MEF2C may initially serve to promote an adaptive hypertrophic response to increased afterload in the $\mathrm{RV}$, but that there is a shift to proapoptotic, fibrotic, and glycolytic pathways during decompensation that is associated with decreased MEF2 activity $(56,57)$ (Figure 1). This shift raises the question of whether there may be increased activity or nuclear localization of HDAC 4 and 5 in the decompensated RV, though this hypothesis has not yet been examined. The decreased MEF2 activity observed in the decompensated RV is in contrast to observations of the linkage between increased MEF2 activity and

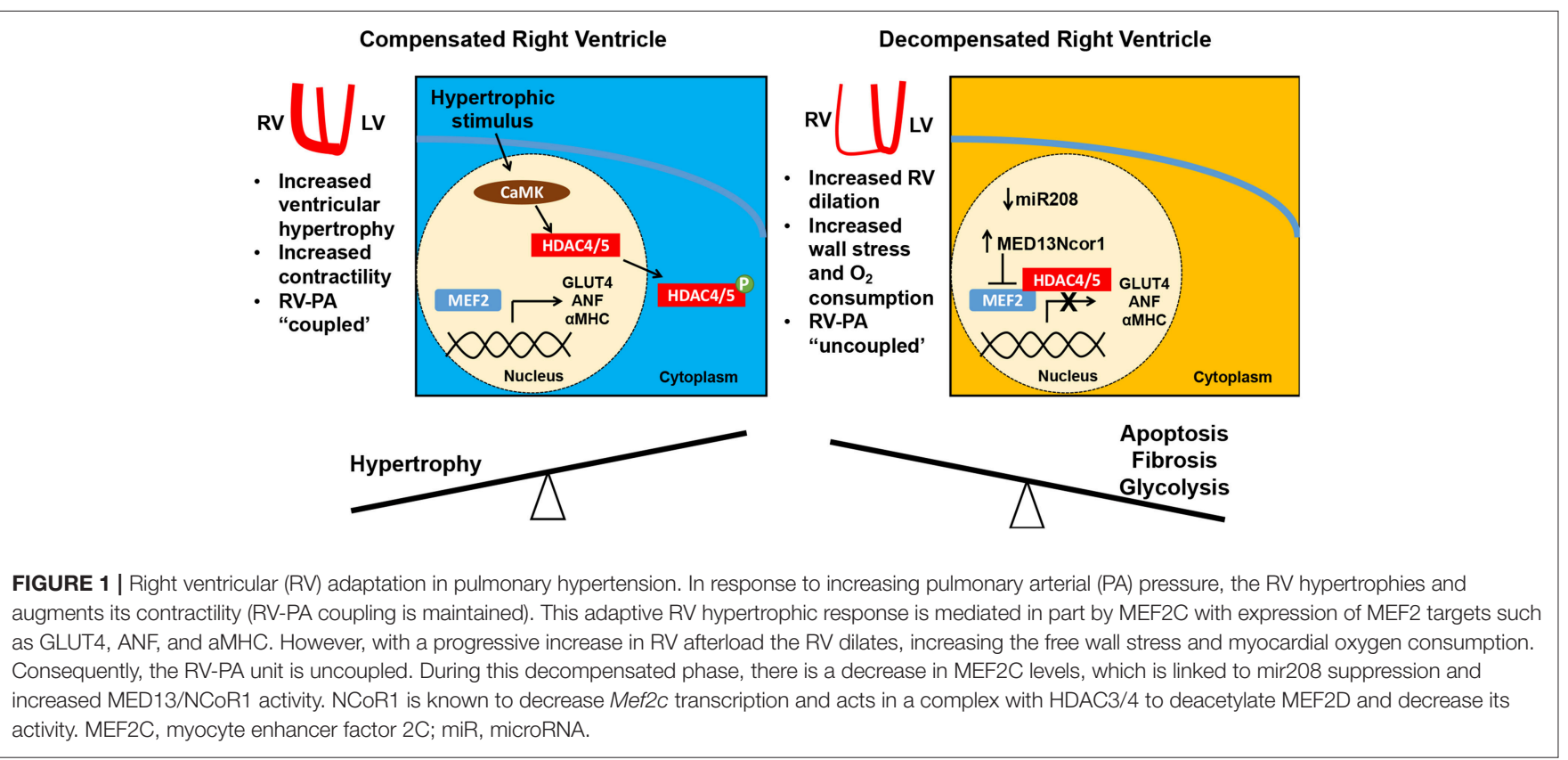

Normal Pulmonary Endothelium

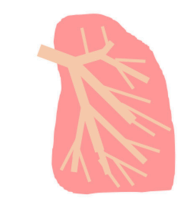

Preserved vessel density, endothelial function, quiescence
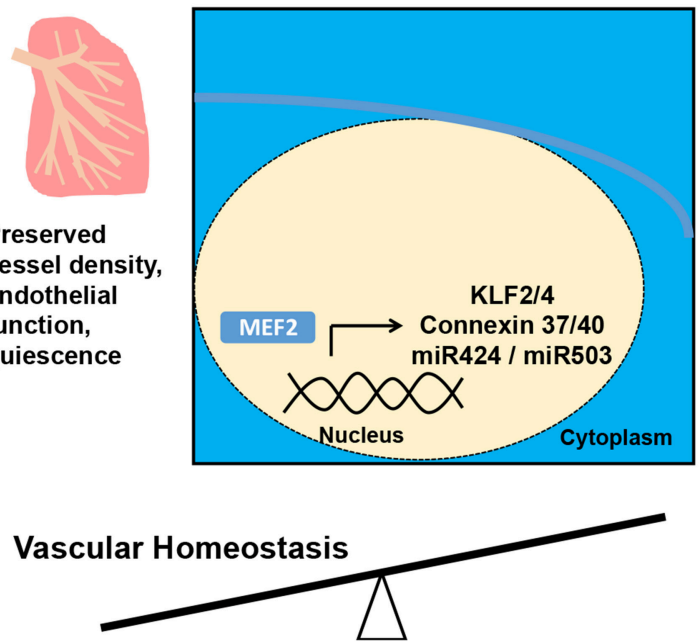

PAH Pulmonary Endothelium

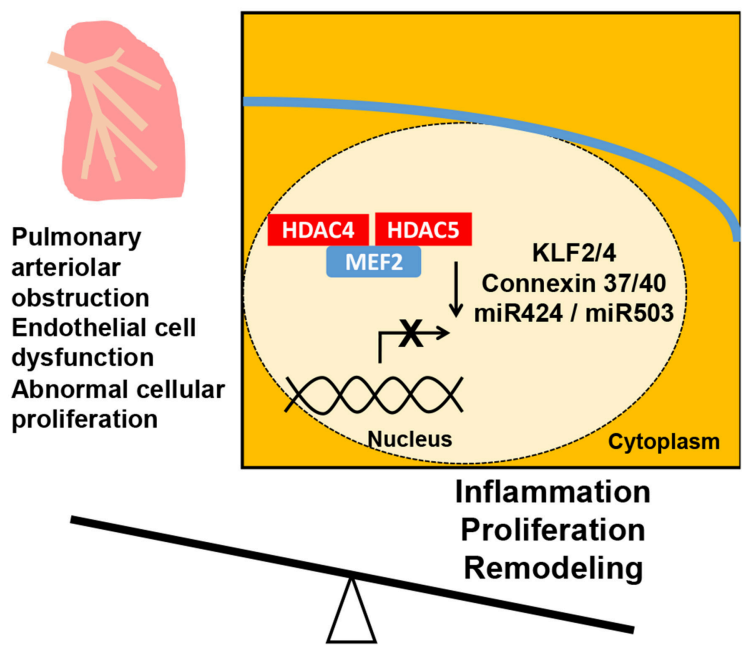

FIGURE 2 | Alteration of the pulmonary vascular endothelium in pulmonary arterial hypertension (PAH). In the normal pulmonary vasculature, MEF2 promotes endothelial function preserving vessel density. In PAH, downregulation of MEF2 from increased nuclear localization of HDAC4 and HDAC5 results in decreased MEF2 activity and decreased expression of antiproliferative miR-424 and miR-503, the vascular homeostatic factors connexins 37 , 40, and the anti-inflammatory and antithrombotic KLF2 and KLF4. These molecular alterations then lead to abnormal endothelial cell proliferation and muscularization of the pulmonary arterioles. MEF2, myocyte enhancer factor; HDAC, histone deacetylase; mir, micro ribonucleic acid. 
pathologic remodeling in the LV. This discrepancy may point to an interventricular difference in function and pathology, and warrants further investigation.

\section{MEF2 IN THE ENDOTHELIUM}

$\mathrm{PAH}$ is of course a disease of the pulmonary vasculature as well, and MEF2 appears to have a protective role in the endothelium (Figure 2). MEF2A and MEF2C are the MEF2 isoforms most highly expressed in endothelium (58). MEF2C promotes endothelial survival, regulates endothelial cytoskeleton and inhibits smooth muscle migration into the intima of the vasculature $(59,60)$. Endothelial specific knock out of $M e f 2 c$ in mice with subsequent exposure to hypoxia leads to increased $\mathrm{PH}, \mathrm{RV}$ hypertrophy (RVH), and muscularization of pulmonary arterioles (61). The transcriptional activity of MEF2C is impaired in PAECs from individuals with $\mathrm{PAH}$ due to increased nuclear localization of inhibitory class IIa HDACs HDAC4 and HDAC5 (58). Decreased MEF2 activity leads to reduction in apelin mediated expression of miR-424 and miR-503, which decrease the pathologic hyperproliferation of endothelial and smooth muscle cells seen in PAH through downregulation of FGF2 and FGFR1 $(58,62)$. Reduced MEF2 activity also decreases the transcription of vascular homeostatic factors connexins 37, 40, and the anti-inflammatory and antithrombotic KLF2 and KLF4 (58, 63-67). Augmentation of MEF2 effects through class IIa HDAC inhibition decreases RVH and right ventricular systolic pressure (RVSP) in monocrotaline and Sugen/hypoxia rat models of $\mathrm{PH}(58,61)$. In summary, MEF2C increases expression of multiple factors that maintain pulmonary vascular homeostasis, MEF2C activity is impaired in $\mathrm{PAH}$, and class IIa HDAC inhibition can restore its function.

\section{HDAC IIA INHIBITION INCREASES MEF2 ACTIVITY}

MEF2, with its apparent protective role in RV function and endothelium in models of $\mathrm{PAH}$, presents an attractive target for therapeutic intervention. As described above, class IIa HDACs bind MEF2 and suppress its activity $(49,50)$. Thus, HDAC inhibitors which would free MEF2 and increase transcription of its targets are of interest as potential disease-modifying agents in $\mathrm{PAH}$.

Both pan HDAC and class specific HDAC inhibitors have been studied in preclinical models of PH (68). Surprisingly, the pan HDAC inhibitor tricostatin A (TSA), in a pulmonary artery banding $(\mathrm{PAB})$ model of $\mathrm{PH}$ in Sprague Dawley (SD) rats leads to worse RV function and increased fibrosis, perhaps secondary to antiangiogenic effects of TSA (69). In contrast,

\section{REFERENCES}

1. Rich S. Right ventricular adaptation and maladaptation in chronic pulmonary arterial hypertension. Cardiol Clin. (2012) 30:257-69. doi: 10.1016/j.ccl.2012.03.004 class I HDAC inhibitor valproic acid does not lead to cardiac fibrosis or decreased capillary density in the same model (69). Administration of benzamide class I HDAC inhibitors to SD rats with hypoxia induced $\mathrm{PH}$ results in decreased $\mathrm{PH}$ with preserved RV function, but has a mild effect on RVH (70).

Notably, class II HDACs, especially class IIb HDAC HDAC6, were shown to increase VEGF expression in mouse cardiac microvascular endothelial cells, raising a concern that class II HDAC inhibition could have anti-angiogenic and deleterious effects similar to those of TSA (69). However, preclinical studies of class IIa HDAC inhibitors, increasing MEF2 activity, have had promising results. The class IIa HDAC inhibitor MC1568, when administered to rats with monocrotaline and Sugen/hypoxia induced $\mathrm{PH}$, decreases $\mathrm{RVH}$, RVSP, and muscularized arterioles without evidence of increased myocardial fibrosis or RV dilatation (58). Apoptosis, as measured by caspase 3 cleavage, is increased in human coronary artery endothelial cells with TSA but not MC1568 administration (58). Class IIa HDAC inhibitors TMP269 and Tasquinimod lead to a reduction in RVSP, RVH, and muscularized arterioles in a Sugen/hypoxia rat PH model (61). Whether the decrease in RVH despite increased MEF2 activity in these studies was due to decreased afterload or another mechanism remains to be further investigated.

\section{CONCLUSION}

RV function is crucial to the outcome of patients with PAH. Understanding the RV's distinct development, structure, and adaptation to changing physiology is key to the development of appropriate management strategies and disease-modifying agents in PAH. MEF2, with its protective role in the face of increased afterload and endothelial dysfunction, is a prime candidate for such interventions. HDAC inhibitors, in particular class IIa HDAC inhibitors that appear to avoid the adverse effects noted with other classes, offer promise as a novel therapeutic strategy in a disease that has proven difficult to treat.

\section{AUTHOR CONTRIBUTIONS}

$\mathrm{KC}$, IS, IC, SR, and HC devised the topic, wrote the manuscript, and prepared the figures.

\section{FUNDING}

This work was supported by funding support from the PVRI (Basic Research Fellowship to KC, Dinosaur Trust BMPR2 Research Grant to HC), and NIH/NHLBI (HL136715 and HL142818 to HC).

2. Ventetuolo CE, Klinger JR. Management of acute right ventricular failure in the intensive care unit. Ann Am Thorac Soc. (2014) 11:811-22. doi: 10.1513/AnnalsATS.201312-446FR

3. Pinsky MR. The right ventricle: interaction with the pulmonary circulation. Crit Care. (2016) 20:266. doi: 10.1186/s13054-016-1440-0 
4. Redington AN, Rigby ML, Shinebourne EA, Oldershaw PJ. Changes in the pressure-volume relation of the right ventricle when its loading conditions are modified. Br Heart J. (1990) 63:45-9. doi: 10.1136/hrt.63.1.45

5. Ingels NB Jr. Myocardial fiber architecture and left ventricular function. Technol Health Care. (1997) 5:45-52.

6. Sallin EA. Fiber orientation and ejection fraction in the human left ventricle. Biophys J. (1969) 9:954-64. doi: 10.1016/S0006-3495(69)86429-5

7. Saleh S, Liakopoulos OJ, Buckberg GD. The septal motor of biventricular function. Eur J Cardiothorac Surg. (2006) 29(Suppl. 1):S126-38. doi: 10.1016/j.ejcts.2006.02.048

8. Belenkie I, Horne SG, Dani R, Smith ER, Tyberg JV.Belenkie I, Horne SG, Dani R, Smith ER, Tyberg JV. Effects of aortic constriction during experimental acute right ventricular pressure loading. Further insights into diastolic and systolic ventricular interaction. Circulation. (1995) 92:546-54. doi: 10.1161/01.CIR.92.3.546

9. Kormos RL, Teuteberg JJ, Pagani FD, Russell SD, John R, Miller LW, et al. Right ventricular failure in patients with the HeartMate II continuous-flow left ventricular assist device: incidence, risk factors, and effect on outcomes. $J$ Thorac Cardiovasc Surg. (2010) 139:1316-24. doi: 10.1016/j.jtcvs.2009.11.020

10. Vonk-Noordegraaf A, Haddad F, Chin KM, Forfia PR, Kawut SM, Lumens J, et al. Right heart adaptation to pulmonary arterial hypertension: physiology and pathobiology. J Am Coll Cardiol. (2013) 62(Suppl. 25):D22-33. doi: 10.1016/j.jacc.2013.10.027

11. Peacock AJ, Vonk Noordegraaf A. Cardiac magnetic resonance imaging in pulmonary arterial hypertension. Eur Respir Rev. (2013) 22:526-34. doi: 10.1183/09059180.00006313

12. Dweik RA, Rounds S, Erzurum SC, Archer S, Fagan K, Hassoun PM, et al. An official American Thoracic Society Statement: pulmonary hypertension phenotypes. Am J Respir Crit Care Med. (2014) 189:345-55. doi: 10.1164/rccm.201311-1954ST

13. Lahm T, Douglas IS, Archer SL, Bogaard HJ, Chesler NC, Haddad F, et al. Assessment of right ventricular function in the research setting: knowledge gaps and pathways forward. An Official American Thoracic Society Research Statement. Am J Respir Crit Care Med. (2018) 198:e15-e43. doi: 10.1164/rccm.201806-1160ST

14. Kawut SM, Al-Naamani N, Agerstrand C, Berman Rosenzweig E, Rowan C, Barst RJ, et al. Determinants of right ventricular ejection fraction in pulmonary arterial hypertension. Chest. (2009) 135:752-9. doi: $10.1378 /$ chest.08-1758

15. Tedford RJ, Mudd JO, Girgis RE, Mathai SC, Zaiman AL, HoustenHarris $\mathrm{T}$, et al. Right ventricular dysfunction in systemic sclerosisassociated pulmonary arterial hypertension. Circ Heart Fail. (2013) 6:953-63. doi: 10.1161/CIRCHEARTFAILURE.112.000008

16. Vonk Noordegraaf A, Westerhof BE, Westerhof N. The relationship between the right ventricle and its load in pulmonary hypertension. J Am Coll Cardiol. (2017) 69:236-43. doi: 10.1016/j.jacc.2016.10.047

17. Hsu S, Houston BA, Tampakakis E, Bacher AC, Rhodes PS, Mathai SC, et al. Right ventricular functional reserve in pulmonary arterial hypertension. Circulation. (2016) 133:2413-22. doi: 10.1161/CIRCULATIONAHA.116.022082

18. Metkus TS, Mullin CJ, Grandin EW, Rame JE, Tampakakis E, Hsu S, et al. Heart rate dependence of the pulmonary Resistance $\mathrm{x}$ Compliance (RC) time and impact on right ventricular load. PLoS ONE. (2016) 11:e0166463. doi: 10.1371/journal.pone.0166463

19. Spruijt OA, de Man FS, Groepenhoff H, Oosterveer F, Westerhof N, VonkNoordegraaf A, et al. The effects of exercise on right ventricular contractility and right ventricular-arterial coupling in pulmonary hypertension. Am J Respir Crit Care Med. (2015) 191:1050-7. doi: 10.1164/rccm.201412-2271OC

20. Chan SY, Rubin LJ. Metabolic dysfunction in pulmonary hypertension: from basic science to clinical practice. Eur Respir Rev. (2017) 26:170094. doi: 10.1183/16000617.0094-2017

21. Yutzey KE, Kirby ML. Wherefore heart thou? Embryonic origins of cardiogenic mesoderm. Dev Dyn. (2002) 223:307-20. doi: 10.1002/dvdy.10068

22. Abu-Issa R, Kirby ML. Heart field: from mesoderm to heart tube. Annu Rev Cell Dev Biol. (2007) 23:45-68. doi: 10.1146/annurev.cellbio.23.090506.123331

23. MacGrogan D, Münch J, de la Pompa JL. Notch and interacting signalling pathways in cardiac development, disease, and regeneration. Nat Rev Cardiol. (2018) 15:685-704 doi: 10.1038/s41569-018-0100-2
24. Buckingham M, Meilhac S, Zaffran S. Building the mammalian heart from two sources of myocardial cells. Nat Rev Genet. (2005) 6:826-35. doi: $10.1038 / \operatorname{nrg} 1710$

25. Prall OW, Menon MK, Solloway MJ, Watanabe Y, Zaffran S, Bajolle F, et al. An Nkx2-5/Bmp2/Smad1 negative feedback loop controls heart progenitor specification and proliferation. Cell. (2007) 128:947-59. doi: 10.1016/j.cell.2007.01.042

26. Sun Y, Liang X, Najafi N, Cass M, Lin L, Cai CL, et al. Islet 1 is expressed in distinct cardiovascular lineages, including pacemaker and coronary vascular cells. Dev Biol. (2007) 304:286-96. doi: 10.1016/j.ydbio.2006.12.048

27. Ma Q, Zhou B, Pu WT. Reassessment of Isl1 and Nkx2-5 cardiac fate maps using a Gata4-based reporter of Cre activity. Dev Biol. (2008) 323:98-104. doi: 10.1016/j.ydbio.2008.08.013

28. Cai CL, Liang X, Shi Y, Chu PH, Pfaff SL, Chen J, et al. Isl1 identifies a cardiac progenitor population that proliferates prior to differentiation and contributes a majority of cells to the heart. Dev Cell. (2003) 5:877-89. doi: 10.1016/S1534-5807(03)00363-0

29. Saga Y, Kitajima S, Miyagawa-Tomita S. Mesp1 expression is the earliest sign of cardiovascular development. Trends Cardiovasc Med. (2000) 10:345-52. doi: 10.1016/S1050-1738(01)00069-X

30. Vincent SD, Buckingham ME. How to make a heart: the origin and regulation of cardiac progenitor cells. Curr Top Dev Biol. (2010) 90:1-41. doi: 10.1016/S0070-2153(10)90001-X

31. Potthoff MJ, Olson EN. MEF2: a central regulator of diverse developmental programs. Development. (2007) 134:4131-40. doi: 10.1242/dev. 008367

32. Edmondson DG, Lyons GE, Martin JF, Olson EN. Mef2 gene expression marks the cardiac and skeletal muscle lineages during mouse embryogenesis. Development. (1994) 120:1251-63.

33. Arnold MA, Kim Y, Czubryt MP, Phan D, McAnally J, Qi X, et al. MEF2C transcription factor controls chondrocyte hypertrophy and bone development. Dev Cell. (2007) 12:377-89. doi: 10.1016/j.devcel.2007.02.004

34. Lin Q, Schwarz J, Bucana C, Olson EN. Control of mouse cardiac morphogenesis and myogenesis by transcription factor MEF2C. Science. (1997) 276:1404-7. doi: 10.1126/science.276.5317.1404

35. Karamboulas C, Dakubo GD, Liu J, De Repentigny Y, Yutzey K, Wallace VA, et al. Disruption of MEF2 activity in cardiomyoblasts inhibits cardiomyogenesis. J Cell Sci. (2006) 119(Pt 20):4315-21. doi: $10.1242 /$ jcs. 03186

36. Naya FJ, Black BL, Wu H, Bassel-Duby R, Richardson JA, Hill JA, et al. Mitochondrial deficiency and cardiac sudden death in mice lacking the MEF2A transcription factor. Nat Med. (2002) 8:1303-9. doi: 10.1038/nm789

37. Kim Y, Phan D, van Rooij E, Wang DZ, McAnally J, Qi X, et al. The MEF2D transcription factor mediates stress-dependent cardiac remodeling in mice. $J$ Clin Invest. (2008) 118:124-32. doi: 10.1172/JCI33255

38. Molkentin JD, Firulli AB, Black BL, Martin JF, Hustad CM, Copeland $\mathrm{N}$, et al. MEF2B is a potent transactivator expressed in early myogenic lineages. Mol Cell Biol. (1996) 16:3814-24. doi: 10.1128/MCB.16. 7.3814

39. Lu CX, Wang W, Wang Q, Liu XY, Yang YQ. A novel MEF2C loss-of-function mutation associated with congenital double outlet right ventricle. Pediatr Cardiol. (2018) 39:794-804. doi: 10.1007/s00246-018-1822-y

40. Kodo K, Nishizawa T, Furutani M, Arai S, Ishihara K, Oda M, et al. Genetic analysis of essential cardiac transcription factors in 256 patients with non-syndromic congenital heart defects. Circ J. (2012) 76:1703-11. doi: 10.1253/circj.CJ-11-1389

41. Molkentin JD, Markham BE. Myocyte-specific enhancer-binding factor (MEF-2) regulates alpha-cardiac myosin heavy chain gene expression in vitro and in vivo. J Biol Chem. (1993) 268:19512-20.

42. Pereira AH, Clemente CF, Cardoso AC, Theizen TH, Rocco SA, Judice CC, et al. MEF2C silencing attenuates load-induced left ventricular hypertrophy by modulating mTOR/S6K pathway in mice. PLoS ONE. (2009) 4:e8472. doi: 10.1371/journal.pone. 0008472

43. Tang CM, Liu FZ, Zhu JN, Fu YH, Lin QX, Deng CY, et al. Myocytespecific enhancer factor 2C: a novel target gene of miR-214-3p in suppressing angiotensin II-induced cardiomyocyte hypertrophy. Sci Rep. (2016) 6:36146. doi: $10.1038 /$ srep36146 
44. Xu J, Gong NL, Bodi I, Aronow BJ, Backx PH, Molkentin JD. Myocyte enhancer factors $2 \mathrm{~A}$ and $2 \mathrm{C}$ induce dilated cardiomyopathy in transgenic mice. J Biol Chem. (2006) 281:9152-62. doi: 10.1074/jbc.M510217200

45. Lu J, McKinsey TA, Nicol RL, Olson EN. Signal-dependent activation of the MEF2 transcription factor by dissociation from histone deacetylases. Proc Natl Acad Sci USA. (2000) 97:4070-5. doi: 10.1073/pnas.080064097

46. Yang SH, Galanis A, Sharrocks AD. Targeting of p38 mitogen-activated protein kinases to MEF2 transcription factors. Mol Cell Biol. (1999) 19:402838. doi: 10.1128/MCB.19.6.4028

47. Wu H, Rothermel B, Kanatous S, Rosenberg P, Naya FJ, Shelton JM, et al. Activation of MEF2 by muscle activity is mediated through a calcineurin-dependent pathway. EMBO J. (2001) 20:6414-23. doi: 10.1093/emboj/20.22.6414

48. Molkentin JD, Lu JR, Antos CL, Markham B, Richardson J, Robbins J, et al. A calcineurin-dependent transcriptional pathway for cardiac hypertrophy. Cell. (1998) 93:215-28. doi: 10.1016/S0092-8674(00)81573-1

49. Lu J, McKinsey TA, Zhang CL, Olson EN. Regulation of skeletal myogenesis by association of the MEF2 transcription factor with class II histone deacetylases. Mol Cell. (2000) 6:233-44. doi: 10.1016/S1097-2765(00)00025-3

50. McKinsey TA, Zhang CL, Lu J, Olson EN. Signal-dependent nuclear export of a histone deacetylase regulates muscle differentiation. Nature. (2000) 408:106111. doi: $10.1038 / 35040593$

51. van Oort RJ, van Rooij E, Bourajjaj M, Schimmel J, Jansen MA, van der Nagel R, et al. MEF2 activates a genetic program promoting chamber dilation and contractile dysfunction in calcineurin-induced heart failure. Circulation. (2006) 114:298-308. doi: 10.1161/CIRCULATIONAHA.105.608968

52. Vega RB, Harrison BC, Meadows E, Roberts CR, Papst PJ, Olson EN, et al. Protein kinases $\mathrm{C}$ and $\mathrm{D}$ mediate agonist-dependent cardiac hypertrophy through nuclear export of histone deacetylase 5. Mol Cell Biol. (2004) 24:837485. doi: 10.1128/MCB.24.19.8374-8385.2004

53. Verzi MP, McCulley DJ, De Val S, Dodou E, Black BL. The right ventricle, outflow tract, and ventricular septum comprise a restricted expression domain within the secondary/anterior heart field. Dev Biol. (2005) 287:134-45. doi: 10.1016/j.ydbio.2005.08.041

54. Paulin R, Sutendra G, Gurtu V, Dromparis P, Haromy A, Provencher $\mathrm{S}$, et al. A miR-208-Mef2 axis drives the decompensation of right ventricular function in pulmonary hypertension. Circ Res. (2015) 116:56-69. doi: 10.1161/CIRCRESAHA.115.303910

55. Yamamoto H, Williams EG, Mouchiroud L, Cantó C, Fan W, Downes M, et al. NCoR1 is a conserved physiological modulator of muscle mass and oxidative function. Cell. (2011) 147:827-39. doi: 10.1016/j.cell.2011.10.017

56. Reddy S, Zhao $\mathrm{M}, \mathrm{Hu} \mathrm{DQ}$, Fajardo $\mathrm{G}, \mathrm{Hu} \mathrm{S}$, Ghosh Z, et al. Dynamic microRNA expression during the transition from right ventricular hypertrophy to failure. Physiol Genomics. (2012) 44:562-75. doi: 10.1152/physiolgenomics.00163.2011

57. Drake JI, Bogaard HJ, Mizuno S, Clifton B, Xie B, Gao Y, et al. Molecular signature of a right heart failure program in chronic severe pulmonary hypertension. Am J Respir Cell Mol Biol. (2011) 45:1239-47. doi: 10.1165/rcmb.2010-0412OC

58. Kim J, Hwangbo C, Hu X, Kang Y, Papangeli I, Mehrotra D, et al. Restoration of impaired endothelial myocyte enhancer factor 2 function rescues pulmonary arterial hypertension. Circulation. (2015) 131:190-9. doi: 10.1161/CIRCULATIONAHA.114.013339

59. Lu YW, Lowery AM, Sun LY, Singer HA, Dai G, Adam AP, et al. Endothelial myocyte enhancer factor $2 \mathrm{c}$ inhibits migration of smooth muscle cells through fenestrations in the internal elastic lamina. Arterioscler Thromb Vasc Biol. (2017) 37:1380-90. doi: 10.1161/ATVBAHA.117.309180
60. Hayashi M, Kim SW, Imanaka-Yoshida K, Yoshida T, Abel ED, Eliceiri B, et al. Targeted deletion of BMK1/ERK5 in adult mice perturbs vascular integrity and leads to endothelial failure. J Clin Invest. (2004) 113:1138-48. doi: 10.1172/JCI200419890

61. Sofer A, Lee S, Papangeli I, Adachi T, Hwangbo C, Comhair S, et al Therapeutic engagement of the HDAC IIA-MEF2 axis improves experimental pulmonary hypertension. Am J Respir Crit Care Med. (2018) 198:1345-8. doi: 10.1164/rccm.201805-0817LE

62. Kim J, Kang Y, Kojima Y, Lighthouse JK, Hu X, Aldred MA, et al. An endothelial apelin-FGF link mediated by miR-424 and miR-503 is disrupted in pulmonary arterial hypertension. Nat Med. (2013) 19:74-82. doi: 10.1038/nm.3040

63. Wang W, Ha CH, Jhun BS, Wong C, Jain MK, Jin ZG. Fluid shear stress stimulates phosphorylation-dependent nuclear export of HDAC5 and mediates expression of KLF2 and eNOS. Blood. (2010) 115:2971-9. doi: 10.1182/blood-2009-05-224824

64. Parmar KM, Larman HB, Dai G, Zhang Y, Wang ET, Moorthy $\mathrm{SN}$, et al. Integration of flow-dependent endothelial phenotypes by Kruppel-like factor 2. J Clin Invest. (2006) 116:49-58. doi: 10.1172/JCI 24787

65. Sohn SJ, Li D, Lee LK, Winoto A. Transcriptional regulation of tissue-specific genes by the ERK5 mitogen-activated protein kinase. Mol Cell Biol. (2005) 25:8553-66. doi: 10.1128/MCB.25.19.8553-8566.2005

66. Kang Y, Kim J, Anderson JP, Wu J, Gleim SR, Kundu $\mathrm{RK}$, et al. Apelin-APJ signaling is a critical regulator of endothelial MEF2 activation in cardiovascular development. Circ Res. (2013) 113:22-31. doi: 10.1161/CIRCRESAHA.113. 301324

67. Kumar A, Lin Z, SenBanerjee S, Jain MK. Tumor necrosis factor alphamediated reduction of KLF2 is due to inhibition of MEF2 by NFkappaB and histone deacetylases. Mol Cell Biol. (2005) 25:5893-903. doi: 10.1128/MCB.25.14.5893-5903.2005

68. Cavasin MA, Stenmark KR, McKinsey TA. Emerging roles for histone deacetylases in pulmonary hypertension and right ventricular remodeling (2013 Grover Conference series). Pulm Circ. (2015) 5:63-72. doi: $10.1086 / 679700$

69. Bogaard HJ, Mizuno S, Hussaini AA, Toldo S, Abbate A, Kraskauskas D, et al. Suppression of histone deacetylases worsens right ventricular dysfunction after pulmonary artery banding in rats. Am J Respir Crit Care Med. (2011) 183:1402-10. doi: 10.1164/rccm.201007-1106OC

70. Cavasin MA, Demos-Davies K, Horn TR, Walker LA, Lemon DD, Birdsey N, et al. Selective class I histone deacetylase inhibition suppresses hypoxia-induced cardiopulmonary remodeling through an antiproliferative mechanism. Circ Res. (2012) 110:739-48. doi: 10.1161/CIRCRESAHA.111. 258426

Conflict of Interest Statement: The authors declare that the research was conducted in the absence of any commercial or financial relationships that could be construed as a potential conflict of interest.

Copyright (C) 2019 Clapham, Singh, Capuano, Rajagopal and Chun. This is an openaccess article distributed under the terms of the Creative Commons Attribution License (CC BY). The use, distribution or reproduction in other forums is permitted, provided the original author(s) and the copyright owner(s) are credited and that the original publication in this journal is cited, in accordance with accepted academic practice. No use, distribution or reproduction is permitted which does not comply with these terms. 